\title{
Distribuição das perícias médicas realizadas no Instituto de Medicina Social e de Criminologia do Estado de São Paulo (IMESC) segundo o tipo de ação judicial
}

\author{
Distribution of medical investigations carried out at the Institute of \\ Social Medicine and Criminology of the State of São Paulo (IMESC) \\ according to the type of lawsuit
}

\author{
Camila Lúcia Dedivitis Tiossi Wild ${ }^{1}$
}

\begin{abstract}
Wild CLDT. Distribuição das perícias médicas realizadas no Instituto de Medicina Social e de Criminologia do Estado de São Paulo (IMESC) segundo o tipo de ação judicial. Saúde, Ética \& Justiça. 2013;18(2):137-40.

RESUMO: O Instituto de Medicina Social e de Criminologia do Estado de São Paulo (IMESC) presta auxílio ao judiciário em ações cíveis, elaborando laudos periciais para subsidiar o juiz em discussões que esbarram em matéria médica. No presente trabalho foram analisadas retrospectivamente 1131 perícias médicas na área clínica realizadas no IMESC, por um mesmo perito, no período de abril 2009 a novembro 2012. A perícia médica mais prevalente foi a ação de interdição $(30,5 \%)$, seguida da securitária $(25 \%)$ e indenizatória $(17 \%)$. Foi observada uma variedade de temas que a perícia judicial civil aborda, fazendo com que o perito médico necessite de amplo conhecimento nas diversas questões de litígio para que possa auxiliar o juízo.
\end{abstract}

PALAVRAS CHAVES: Prova pericial; Decisões periciais.

1. Médica perita do IMESC, médica assistente do Instituto da Criança do Hospital das Clínicas da Universidade de São Paulo, médica assistente do Hospital Infantil Darcy Vargas, Mestre em medicina pela Faculdade de Ciências Médicas da Santa Casa de SP, bacharel em direito pela Universidade de São Paulo, aluna de pós-graduação em medicina do trabalho e perícias médicas da Unicastelo.

Endereço para correspondência: R. Barra Funda, 824 - Barra Funda, São Paulo - SP, 01152-000. Aos cuidados de Dra. Camila Lúcia Dedivitis Tiossi Wild - perita médica. E-mail: camilatiossi@uol.com.br 


\section{INTRODUÇÃO}

$\mathbf{O}$ Instituto de Medicina Social e de Criminologia de São Paulo (IMESC) é uma autarquia vinculada à Secretaria da Justiça e da Defesa da Cidadania do Estado de São Paulo e sua origem remonta ao ano de $1970^{1}$, quando começou a existir legalmente. Tem as seguintes atribuições: 1. promover a formação e o treinamento de pessoal especializado, mediante a realização de cursos e congressos nos ramos da Medicina Legal, da Medicina Social, da Medicina do Trabalho, da Criminologia, da Criminalística, da Identificação, da História da Medicina e da Ética Profissional, 2. executar pesquisas nos ramos citados anteriormente, 3. prestar colaboração à Universidade de São Paulo - USP, em caráter de reciprocidade, nas atividades docentes e de pesquisa, referentes a matéria técnico-científica compreendida no âmbito de suas atribuições, na forma que for estabelecida em convênio; 4. cooperar com os órgãos da Administração Direta e Indireta do Estado, na esfera de suas atribuições; 5 . realizar perícias, exames de personalidade e de capacidade profissional, requisitados pelas autoridades competentes; 6 . difundir o resultado de suas atividades e de outras matérias relacionadas com a sua área de atribuições; 7.participar da prática de uma política criminal de prevenção do delito e tratamento dos delinqüentes, segundo os modernos princípios penais e penitenciários. (fonte: site imesc- www.imesc.sp.gov.br).

Perícia é ato traduzido por laudo emitido por profissional que detém conhecimento específico, em matéria a ser discutida. Quando elaborado por um médico, será uma perícia médica ${ }^{2,3}$.

O IMESC ${ }^{1}$ presta auxílio ao judiciário, em ações cíveis, elaborando laudos médico-periciais para subsidiar o juiz, em discussões que esbarram em matéria médica. Toda situação em que ocorra um dano à pessoa, quer seja físico (com repercussão morfológica ou funcional) ou psíquico, e existindo a necessidade do estabelecimento da causa do dano, de sua quantificação, do custo de reparação, entre outros, há a necessidade da discussão de tais dados por especialistas (médico perito, no caso) ${ }^{2,3,4}$. Diversas são as ações que comportam tais discussões, com a necessidade da participação do médico perito. Como exemplos: ações de indenização para reparação de danos advindos de acidente do trabalho, acidente de trânsito, discussões sobre erro médico, reparações onde há erro médico, entre tantas outras situações.

\section{OBJETIVO}

O presente trabalho tem por objetivo avaliar as pericias médicas civis realizadas no IMESC de acordo com o tipo de ação judicial.

\section{MATERIAL E MÉTODO}

Análise retrospectiva de 1131 perícias médicas na área clínica realizadas no IMESC por um mesmo perito no período de abril de 2009 a novembro de 2012. O período de tempo escolhido decorre dos arquivos disponibilizados para a pesquisa, desde o início de atuação do perito no IMESC até a realização da presente pesquisa. Foram avaliadas todas as perícias do mesmo perito (sem exclusão), por meio de coleta de dados.

Foram avaliados o tipo de perícia (ação processual), realização de quesitos complementares, necessidade de avaliações subsidiárias, solicitação de prontuários e exames subsidiários. Os quesitos complementares foram analisados de forma geral, ou seja, se foram ou não requisitados, não se pesquisando quem os solicitou.

\section{RESULTADOS}

As perícias cíveis incluíram (Gráfico 1):

- 345 perícias foram do tipo interdição.

- 283 perícias foram do tipo securitário, sendo a maioria de cobrança de seguro DPVAT (Seguro de Danos Pessoais Causados por Veículos Automotores de Vias Terrestres).

- 192 perícias foram do tipo indenizatório, abrangendo temas diversos como: lesão corporal, extravios de exames subsidiários, erros laboratoriais, aquisição de doenças infecto-contagiosas e outras, requisição de pagamento de salário devido doença, isenção de imposto de renda devido doença grave, entre outras.

- 175 perícias foram do tipo erro médico, tendo que ser analisados os atendimentos de todos os profissionais de saúde envolvidos.

- 59 perícias foram previdenciárias, seja para requisição de aposentadoria e/ou de benefícios.

- 32 perícias foram do tipo obrigação de fazer, requisitando do estado tratamento medicamentoso específico para diversas doenças.

- 45 perícias incluíram avaliação da idade, exclusão de pensão alimentícia por capacidade laboral, mudança de sexo na identidade.

Em 70 pericias $(6 \%)$ houve necessidade de avaliação de especialistas que incluíram: dentista especialista em bucomaxilo, psiquiatra, psicólogo, ortopedista, neurologista, otorrinolaringologista, oftalmologista, cirurgia geral, obstetrícia, urologista e anestesiologia. Prontuários médicos e exames subsidiários tiveram que ser solicitados em $3,8 \%$. A resposta a quesitos complementares ocorreu em 13,5\% das perícias (Gráfico 2). Em 3 perícias o perito encontrava-se impedido para sua realização devido ter relações trabalhistas com uma das partes. 
Gráfico 1 - Tipos de perícia

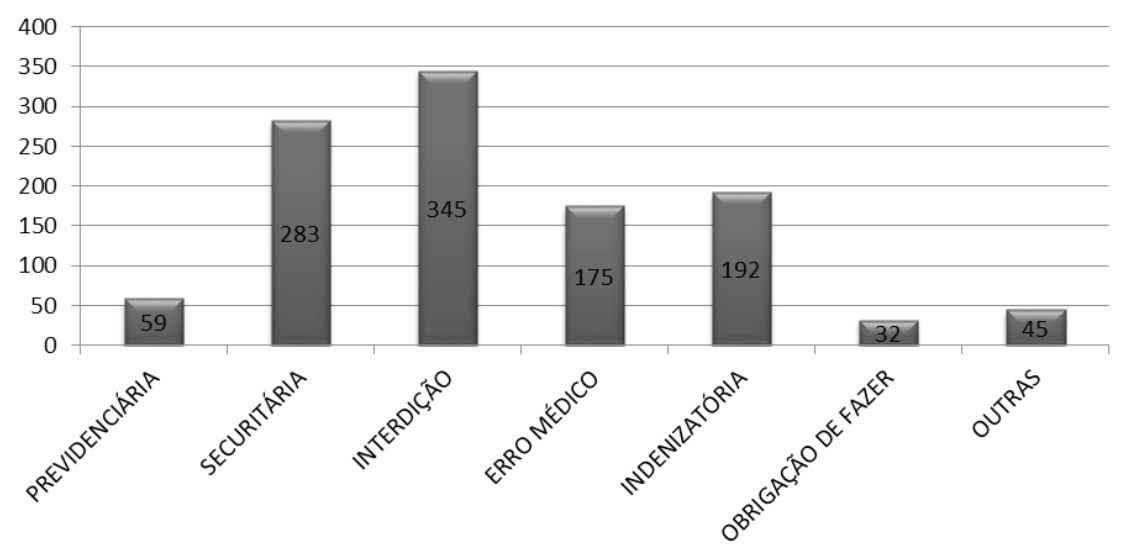

Gráfico 2 - Procedimentos solicitados

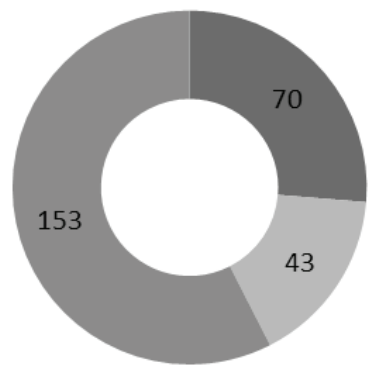

\author{
- AVALIAÇÕES \\ ESPECIALIDADES \\ - SOLICITAÇÃO DE \\ PRONTUÁRIOS E EXAMES \\ QUESITOS \\ COMPLEMENTARES
}

\section{DISCUSSÃO}

Na prova pericial há uma esperança muito grande de contribuição à justiça social, desde que ela esteja firmada em bases científicas, que tenha respostas para um número razoável de dúvidas ainda residuais e que se assente sobre a credibilidade e a moralidade de quem subscreve o laudo. A perícia não é apenas um amontoado de regras técnicas, mas constitui-se na contribuição da medicina nas questões do direito ${ }^{3,5,6}$.

Além das implicações de ordem ética e moral que devem existir na prática da prova pericial médica, há outros problemas de muita importância a partir da análise dos tribunais e da administração pública. O primeiro deles é a dificuldade que os julgadores têm de adentrar nesse mundo da perícia especializada, de métodos e técnicas tão complexos, tanto no que se refere ao aspecto analítico dos resultados, quanto aos procedimentos mais particularizados ${ }^{6}$

Assim, é aconselhável não esquecer que os resultados dos laboratórios e dos serviços encarregados das provas, como, por exemplo, as realizadas em DNA, devem ser sempre avaliadas com muito rigor. Este controle de qualidade tem de ser periodicamente exigido, para que não se venha a acreditar em todo e qualquer resultado numa prova tão delicada, especialmente levando em conta a precariedade dos serviços que, infortunadamente, nos leva a duvidar de suas possibilidades ${ }^{6,7}$.

Por outro lado, não se pode esquecer que algumas perícias realizadas dependem de técnicas requintadas e complexas, as quais obrigam o especialista a treinamentos constantes, atitudes cautelosas e posturas éticas exemplares. Entre nós, por exemplo, não existe nenhum organismo público ou privado que exerça fiscalização constante como controle de qualidade, e por isso não se tem como padronizar métodos e técnicas, nem muito menos como avaliar as condições operacionais dos laboratórios e a capacidade de seus técnicos.

Observou-se, no presente trabalho, a variedade de temas que a pericia judicial civil aborda, fazendo com que o perito médico necessite de amplo conhecimento nas diversas questões de litígio onde o ato médico atua como 
prova e elucidação do juízo.

A responsabilidade médica em toda a sua amplitude é definida como a obrigação de ordem civil, penal ou administrativa a que estão sujeitos os médicos, no exercício profissional quando de um resultado lesivo ao paciente, por imprudência, imperícia ou negligência. $\mathrm{O}$ erro médico é, por isso, distinto do acidente imprevisível e também diferente do mal incontrolável. O erro médico é constituído de cinco elementos: o agente; o ato profissional; a ausência de dolo; a existência de dano; e a relação causal entre o ato e o dano ${ }^{6}$. Conseguir fazer um laudo pericial que permita ao juiz caracterizar ou não o erro médico é o principal objetivo do perito.

Perícias em ações iniciadas por "erro médico" ocorreram em $15,5 \%$ do total. Nesses casos a pericia é encaminhada para uma comissão de erro médico do IMESC, sendo avaliada por mais 3 peritos que emitem sua opinião sobre o laudo apresentado, aprovando-o ou fazendo sugestões para sua reformulação. A avaliação do laudo pela equipe é de grande valia, visto que permite a discussão e a análise de assunto que muitas vezes é difícil. A maioria das perícias não necessitou de avaliações de outras especialidades, tendo sido solicitada somente em 6\% dos casos. Prontuários médicos e exames subsidiários tiveram que ser solicitados em 3,8\% do total. A resposta a quesitos complementares ocorreu em $13,5 \%$ das perícias. Tal número é subestimado, uma vez que o retorno ao IMESC de quesitos complementares ocorre meses após a entrega do laudo pericial, e muitas das perícias analisadas ainda não apresentaram tempo para a chegada dos quesitos complementares.

\section{CONCLUSÃO}

O médico perito se depara com as mais diversas situações, tendo que abranger um vasto conhecimento nas diversas áreas da medicina. Além do conhecimento médico é necessário saber o escopo da lide, sendo importante a análise da exordial, da contestação e do despacho saneador para emitir um laudo pericial que atenda ao solicitado no pedido da ação processual. Em nossa casuísta encontramos diversos tipos de ações civis, a mais prevalente foi a ação de interdição (30,5\%), seguida da securitária (25\%) e indenizatória $(17 \%)$.

O erro médico é a perícia mais trabalhosa, sendo analisada por uma junta médica. Tal medida estabelece um parâmetro de qualidade para esse tipo de perícia e fortalece o laudo pericial.

Agradecimentos: Ao IMESC pela colaboração na coleta da amostragem e liberação para publicação. À UNICASTELO pela conclusão de curso em perícias médicas.

Wild CLDT. Distribution of medical investigations carried out at the Institute of Social Medicine and Criminology of the State of São Paulo (IMESC) according to the type of lawsuit. Saúde, Ética \& Justiça. 2013;18(2):137-40

\begin{abstract}
The Institute of Social Medicine and Criminology of the State of São Paulo (IMESC) provides legal aid in civil suits, preparing expert reports to support the judge in discussions related to the medical field. In the present study 1131 expert clinical medical reports, performed by a single expert at IMESC, from April 2009 to November 2012, were analyzed retrospectively. The most prevalent expert medical reports were for action ban claims $(30.5 \%)$, insurance claims $(25 \%)$ and indemnity claims (17\%). A variety of topics that civil judicial investigation addresses were observed, from which it was determined that the medical expert needs extensive knowledge in various litigation matters that may be useful in the judgment.
\end{abstract}

KEYWORDS: Expert testimony; Judicial decisions.

\title{
REFERENCIAS
}

1. Instituto de Medicina Social e de Criminologia de São Paulo [homepage na Internet]. São Paulo: Governo do Estado de São Paulo; 1999 [atualizada em 2013 set 16]. Disponível em: http://www.imesc.sp.gov.br

2. Gomes H. Medicina Legal. $33^{\mathrm{a}}$ ed. Rio de Janeiro: Editora Freitas Barros; 2003.

3. França GV. Fundamentos da Medicina Legal. $2^{\mathrm{a}}$ ed. Rio de Janeiro: Guanabara Koogan; 2012.

4. Buono Neto A, Buono EA. Pericias Judiciais na Medicina do Trabalho. $3^{\text {a }}$ ed. São Paulo: LTR; 2008.
5. Motta RC. Conceitos Básicos de Perícia Médica. Campinas: Editora Átomo; 2012.

6. Fernades JN. Erro Médico e Responsabilidade Civil [Monografia na Internet]. São Paulo: Pós-graduação da Faculdade de Direito da Universidade Presbiteriana Mackenzie; 2010. Disponível em: http://www.jurisway.org. br/v2/dhall.asp?id_dh $=5527$

7. Dantas RAA. Perícia Médica - estabelecendo nexo, avaliando danos e constatando incapacidade. São Paulo: LTR; 2010. 